\title{
Development of Mental Health Indicators in Korea
}

\author{
Hyeree Han', Dong Hyun Ahn², Jinhee Song ${ }^{1,3}$, Tae Yeon Hwang ${ }^{4}$ and Sungwon Roh ${ }^{1,5} \bowtie$ \\ ${ }^{1}$ Department of Mental Health Research, Seoul National Hospital, Ministry of Health and Welfare, Seoul, Republic of Korea \\ ${ }^{2}$ Department of Psychiatry, Hanyang University College of Medicine, Seoul, Republic of Korea \\ ${ }^{3}$ Department of Social Welfare, Catholic University of Korea, Bucheon, Republic of Korea \\ ${ }^{4} \mathrm{WHO}$ Collaborating Center for PSR and CMH, Yongin Mental Hospital, Yongin, Republic of Korea \\ ${ }^{5}$ Center for Addiction Medicine, Department of Psychiatry, Massachusetts General Hospital, Harvard Medical School, Boston, MA, USA
}

Objective Promoting mental health and preventing mental health problems are important tasks for international organizations and nations. Such goals entail the establishment of active information networks and effective systems and indicators to assess the mental health of populations. This being said, there is a need in Korea develop ways to measure the state of mental health in Korea.

Methods This paper reviews the mental health indicator development policies and practices of seven organizations, countries, and regions: WHO, OECD, EU, United States, Australia, UK, and Scotland. Using Delphi method, we conducted two surveys of mental health indicators for experts in the field of mental health. The survey questionnaire included 5 domains: mental health status, mental health factor, mental health system, mental health service, and quality of mental health services. We considered 124 potential mental health indicators out of more than 600 from indicators of international organizations and foreign countries.

Results We obtained the top 30 mental health indicators from the surveys. Among them, 10 indicators belong to the mental health system. The most important five mental health indicators are suicide rate, rate of increase in mental disorder treatment, burden caused by mental disorders, adequacy of identifying problems of mental health projects and deriving solutions, and annual prevalence of mental disorders.

Conclusion Our study provides information about the process for indicator development and the use of survey results to measure the mental health status of the Korean population. The aim of mental health indicator development is to improve the mental health system by better grasping the current situation. We suggest these mental health indicators can monitor progress in efforts to implement reform policies, provide community services, and involve users, families and other stakeholders in mental health promotion, prevention, care and rehabilitation.

Psychiatry Investig 2012;9:311-318

Key Words Mental health, Mental health indicator, Development.

\section{INTRODUCTION}

According to the results of an epidemiological survey on mental disorders, the lifetime prevalence of mental disorders the percentage of population experiencing one or more mental disorders through life - in Korean adults (at the age of 1864 ) is as high as $27.6 \%{ }^{1}$ Throughout the world as well, 120 million people are suffering depression and less than $25 \%$ of them are known to get adequate treatment. ${ }^{2}$ Moreover, social

Received: May 17, 2012 Revised: July 19, 2012

Accepted: August 5, 2012 Available online: November 14, 2012

$\triangle$ Correspondence: Sungwon Roh, MD, PhD

Department of Mental Health Research, Seoul National Hospital, Ministry of Health and Welfare, 398 Neungdong-ro, Gwangjin-gu, Seoul 143-711, Republic of Korea

Tel: +82-2-2204-0292, Fax: +82-2-2-2204-0280, E-mail: swroh@korea.kr

(a) This is an Open Access article distributed under the terms of the Creative Commons Attribution Non-Commercial License (http://creativecommons.org/licenses/bync/3.0) which permits unrestricted non-commercial use, distribution, and reproduction in any medium, provided the original work is properly cited. and economic burdens caused by mental disorders are increasing steadily, and according to the Global burden of disease project of the World Health Organization (WHO), mental disorders such as depression, alcohol use disorder, bipolar affective disorder and schizophrenia are included in the 20 major causes of disability. In particular, unipolar depressive disorder, which makes the biggest contribution to disease burden among mental disorders, ranked third in terms of contribution to disease burden in 2004 and is expected to be first in $2030 .{ }^{3}$ What is more, mental disorders show early onset age and cause high indirect expenses resulting from the reduction or loss of productivity at workplaces, and consequently they impose high economic burdens on society compared to physical diseases. Nevertheless, mental disorders are generally overlooked by policy makers due to lower mortality than physical diseases and social prejudice against mental disorders.

In order to reduce the serious social and economic impacts 
of mental health problems, it is necessary to survey the general status and level of mental health of the corresponding country and to monitor the trend of change periodically. Particularly in these days, statistical data are used in setting the priority of national policies or evaluating national projects and therefore it is necessary to create various mental health indicators through statistical surveys or reports and to utilize them in policy making. That is, mental health indicators are essential for monitoring people's mental health status in a country, developing mental health policies, and evaluating the performance of such policies. In addition, mental health indicators are required for comparison and benchmarking among countries.

Developed countries have developed mental health indicators systematically based on theoretical grounds as national projects not only for surveying people's mental health status and monitoring its trends but also for providing scientific grounds to policy makers and monitoring the processes and outcomes of policies. On the contrary, few mental health indicators have been developed in Korea. As to statistical data and indicator-related studies in Korea, epidemiological surveys on mental disorders and surveys on disabled persons are conducted in every five years and these surveys cover part of population with mental disorders. In addition, the National Health and Nutrition Survey collect data on mental health such as activity restriction caused by mental disorder, stress awareness level, depression and suicide impulse, and on drinking and smoking. Except these surveys, there are few national projects for monitoring mental health in Korea.

This study was conducted in order to review the current state of mental health indicator development in international organizations and major foreign countries and, based on the results, to develop and propose mental health indicators that can determine and monitor the current level of mental health in Korea, set the priority of promotion or resource allocation in projects to improve mental health, and enable international comparison.

\section{METHODS}

\section{Concept of mental health indicator}

Mental health is one's state of well-being that enables the person to display his/her abilities, to cope with daily stress, to work productively and to contribute to community. Mental health in such a positive sense becomes the base of well-being and effective roles for individuals and community. In a positive sense, mental health may involve both health and diseases and, accordingly, everybody desires mental health and feels subjective health regardless of whether he/she has a mental disorder. $^{4}$

Health indicators are scales not only on the health status of a population group but also on the general level or characteristic of all relevant items including health policy, healthcare system, healthcare resource, natural environment, size and composition of population, and people's perception and value of health. ${ }^{5}$ That is, they express the quantitative and qualitative aspects of health by comprehensively indicating systems and statuses related to a population group's health promotion and prevention of diseases. ${ }^{6}$

Accordingly, 'mental health indicators', which combines the two concepts, are scales showing people's mental disorders as well as their positive mental health including subjective wellbeing and expressing the quantitative and qualitative state of policies and services promoted to solve mental health problems, to promote mental health and to prevent mental disorders. That is, these indicators are used to measure various aspects of mental health system like population groups' need of mental health services (e.g., the percentage of population belonging to vulnerable groups), resources invested in mental health service systems (e.g., the number of mental health professionals per 100,000 persons, and the percentage of budgets for mental health promotion programs in budgets for general health promotion), quality of service activities including the ways of delivering protection (e.g., the annual number of mental inpatients per 100,000 persons), and the effect of mental health services in service consumers (e.g., annual suicide rate, symptom reduction, disability level, quality of life). ${ }^{\text {? }}$

\section{Indicator development in international organizations and other developed countries}

Recently, several international organizations promoted indicator development projects. The Organisation for Economic Co-operation and Development (OECD) conducted the Health Care Quality Indicators Project, through which it defined mental health as one of the five priority areas, reviewed indicators in the member countries, and developed internationally comparable indicators on the quality of mental health. ${ }^{8} \mathrm{WHO}$ performed a indicator development project for evaluating mental health policies and services usable in underdeveloped countries in order to solve the problem that over $24 \%$ of 202 areas, including the member states, associated members, territories, and areas, did not have systems for collecting and reporting mental health information and that mental health evaluation and monitoring tools used in developed countries are not applicable to developing and underdeveloped countries in terms of objective, scope, structure and contents. ${ }^{9}$ The European Union (EU) also promoted the Mental Health Information and Determinants for the European Level (MINDFUL) project based on previous projects for improvement in mental health information and comparison among its member countries with the object of expanding the scope of 
mental health monitoring systems so that they comprehend not only negative mental health but also positive mental health, mental health promotion, and mental disorder prevention. ${ }^{10}$

Among individual countries, the U.S., Australia, the U.K., Scotland, etc. have developed indicators in order to monitor the performance and services of mental health. The U.S. developed indicators on the performance of mental health services to meet consumers' needs actively, ${ }^{11}$ and Australia developed indicators on the performance of mental health services in public sectors in connection to the strategic directions of national mental health plans and characteristically it included indicators related to safety. ${ }^{12}$ In the U.K., mental health indicators have been used in evaluating the performance of the Mental Health Trust since 2001, ${ }^{13}$ and the indicators were designed jointly by the government, the Commission for Health Improvement, and the Ministry of Health. Developed indicators aim to help people understand the performance of community health services and to provide information easily and conveniently, and every year new indicators are developed in the process of setting the goals of the National Health Service in order to reflect changes timely and evaluate performance properly. ${ }^{14}$ Scotland gives national priority to mental health promotion and promotes national visions such as people's mental health, quality of life, welfare, and social integration of those with mental disorders or mental health problems. Moreover, it has defined the concept of mental health in two aspects, namely, mental health problems such as anxiety and positive mental health such as satisfaction with life and positive relations with others, and developed mental health indicators focusing on the measurement of positive mental health. ${ }^{15} \mathrm{Ta}-$ ble 1 summarizes the current state of indicator development in international organizations and major countries as presented above.

The characteristics of mental health indicator development in foreign countries are as follows. First, the objectives of mental health indicator development reflect each country's national mental health strategies and aim at measuring and monitoring the performance of current national mental health policies for mental health promotion. In case of international organizations, indicators are developed mainly to compare the quality of mental health among countries. Second, most countries are making efforts to build up a comprehensive frame including the performance of mental health policies, the provision of services, each population group's current mental health status, etc. in order to measure the performance of mental health services. Third, the concept of mental health is being expanded so that it connotes not only mental disorders but also personal protection factors of positive mental health such as resilience, self-esteem and self-efficacy. Fourth, with regard to the contents of indicators, consumers' viewpoint emphasizing con- sumers' experience in provided mental health services is being introduced in addition to the current state of mental health like mental disorders and the contents of mental health services. Introducing these kinds of indicators will contribute to changing mental health services consumer-centered. Fifth, indicator systems for inter-regional comparison and frameworks for standardized measurements are being developed. Sixth, the development of mental health indicators does not take place in a short period but goes through long-term refinement and revision.

\section{Principles of developing mental health indicators in Korea}

This study attempted to develop indicators that reflect the current state of mental health in Korea, the objectives of national policies and people's needs of mental health, and are internationally comparable. In addition, indicators were developed with the object of enhancing quality of mental health, improving mental health facilities and personnel, upgrading the quality of mental health service, respecting the human rights of people with mental disorders, and using limited mental health resources efficiently and effectively.

For the development of mental health indicators in Korea, we made an effort to include mental health indicators of Health Plan $2010^{16}$ and the National Mental Health Commission report ${ }^{17}$ (Table 2). Health Plan 2010 was a national plan intended to improve the accessibility of mental health service, the level of national mental health and the quality of life of people with mental disorders. The National Mental Health Commission developed some indicators to assess community mental health services.

In developing indicators, we focused on adults and the scope of indicators comprehended mental health problems including mental disorders, resources including manpower, facilities and finance, mental health services, risk and protection factors, etc. Moreover, the scope of mental health services was divided into five domains, that is, mental health status, mental health factor, mental health system, mental health service, and the quality of mental health services so that it includes prevention, treatment, continuous management and early interventions, and divided again into 21 subdomains according to the nature of indicators (Table 3).

'Mental health status' covers positive mental health and mental health problems including mental disorders, and 'mental health factor' covers personal factors and environmental factors that may affect mental health. 'Mental health system' includes indicators related to mental health resources and covered policies and plans related to mental health, organizations and human resources involved in mental health services, and budgets and finance. 'Mental health service' comprehends all 
Table 1. Indicator development of international organizations and other countries

\begin{tabular}{|c|c|c|c|}
\hline $\begin{array}{c}\text { International } \\
\text { organization } \\
\text { /Country }\end{array}$ & Data source & Indicator category (domain) & $\begin{array}{l}\text { No. of } \\
\text { indicators }\end{array}$ \\
\hline OECD & $\begin{array}{l}\text { Indicators for the Quality } \\
\text { of Mental Health Care }\end{array}$ & $\begin{array}{l}\text { Continuity of care } \\
\text { Coordination of care } \\
\text { Treatment } \\
\text { Patient outcomes }\end{array}$ & $\begin{array}{l}4 \text { domains } \\
12 \text { indicators }\end{array}$ \\
\hline WHO & WHO-AIMS & $\begin{array}{l}\text { Policy and legislative framework } \\
\text { Mental health services } \\
\text { Mental health in primary health care } \\
\text { Human resources } \\
\text { Public education and links with other sectors } \\
\text { Monitoring and research }\end{array}$ & $\begin{array}{c}6 \text { domains } \\
28 \text { aspects } \\
156 \text { indicators }\end{array}$ \\
\hline $\mathrm{EU}$ & MINDFUL & $\begin{array}{l}\text { Health status: Cause specific mortality } \\
\text { Health status: Morbidity, disease specific } \\
\text { Health status: Morbidity, generic } \\
\text { Determinants of health: Personal conditions } \\
\text { Determinants of health: Social and cultural conditions } \\
\text { Health systems: Prevention, health protection and promotion } \\
\text { Health systems: Health resources } \\
\text { Health systems: Health care utilization; psychiatric care and social services } \\
\text { Health systems: Expenditure }\end{array}$ & $\begin{array}{l}9 \text { domains } \\
35 \text { indicators }\end{array}$ \\
\hline US & $\begin{array}{l}\text { MHSIP consumer-oriented } \\
\text { mental health report card }\end{array}$ & $\begin{array}{l}\text { Access } \\
\text { Appropriateness } \\
\text { Outcomes } \\
\text { Prevention }\end{array}$ & $\begin{array}{l}4 \text { domains } \\
44 \text { indicators }\end{array}$ \\
\hline Australia & $\begin{array}{l}\text { Key Performance Indicators } \\
\text { for Australian Public Mental } \\
\text { Health Services }\end{array}$ & $\begin{array}{l}\text { Effective } \\
\text { Appropriate } \\
\text { Efficient } \\
\text { Accessible } \\
\text { Continuous } \\
\text { Responsive } \\
\text { Capable } \\
\text { Safe } \\
\text { Sustainable }\end{array}$ & $\begin{array}{c}9 \text { domains } \\
24 \text { subdomains } \\
15 \text { indicators }\end{array}$ \\
\hline UK & $\begin{array}{l}\text { Performance assessment } \\
\text { 2008/2009 Mental health } \\
\text { trust indicators }\end{array}$ & $\begin{array}{l}\text { Data quality on ethnic group } \\
\text { Patterns of care from mental health minimum data set } \\
\text { Completeness of the mental health minimum data set } \\
\text { Access to crisis resolution home treatment } \\
\text { Child and adolescent mental health services } \\
\text { Care programme approach } 7 \text { day follow up } \\
\text { Delayed transfer of care } \\
\text { Best practice in mental health services for people with a learning disability } \\
\text { Experience of patients } \\
\text { Numbers of drug misusers in effective treatment } \\
\text { NHS staff satisfaction }\end{array}$ & 11 indicators \\
\hline Scotland & $\begin{array}{l}\text { Establishing a core set of national, } \\
\text { sustainable mental health } \\
\text { indicators for adults }\end{array}$ & $\begin{array}{l}\text { High level constructs: positive mental health and mental health problems } \\
\text { Contextual constructs: individual, community, and structural }\end{array}$ & $\begin{array}{l}2 \text { categories } \\
55 \text { indicators }\end{array}$ \\
\hline
\end{tabular}

OECD: Organisation for Economic Co-operation and Development, WHO: World Health Organization, AIMS: Assessment Instrument for Mental Health Systems, EU: European Union, MINDFUL: Mental Health Information and Determinants for the European Level, MHSIP: Mental Health Statistics Improvement Program, NHS: National Health Service 
Table 2 . Mental health related indicators in Korea

\begin{tabular}{|c|c|c|c|}
\hline Source & \multicolumn{2}{|c|}{ Indicator category (domain) } & No. of indicators \\
\hline \multirow[t]{4}{*}{ Health Plan 2010} & \multicolumn{2}{|c|}{ Mental health promotion and prevention of mental illness } & 4 \\
\hline & \multicolumn{2}{|c|}{ Establishment system for comprehensive mental health care } & 4 \\
\hline & \multicolumn{2}{|c|}{ Establishment system of treatment, rehabilitation and residential services } & 5 \\
\hline & \multicolumn{2}{|c|}{ Protection of rights and interests of people with mental disorders and improvement of awareness } & 2 \\
\hline \multirow{7}{*}{$\begin{array}{l}\text { National Mental } \\
\text { Health Commission }\end{array}$} & \multicolumn{2}{|c|}{ Relevance of mental health plan } & 4 \\
\hline & \multirow[t]{2}{*}{ Structure assessment } & Budget & 2 \\
\hline & & Infrastructure of mental health services & 9 \\
\hline & \multirow[t]{2}{*}{ Process assessment } & Provision of mental health service & 7 \\
\hline & & Operating organization & 2 \\
\hline & \multicolumn{2}{|l|}{ Outcome assessment } & 4 \\
\hline & \multicolumn{2}{|l|}{ Monitoring assessment } & 5 \\
\hline
\end{tabular}

Table 3. Expert survey results of mental health indicator categories

\begin{tabular}{|c|c|c|c|}
\hline Domain & $\begin{array}{c}\text { Mean of importance } \\
\text { (ranking) }\end{array}$ & Subdomain & $\begin{array}{c}\text { Mean of importance } \\
\text { (ranking) }\end{array}$ \\
\hline \multirow[t]{2}{*}{ Mental health status } & $4.82(3)$ & Positive mental health & $4.09(20)$ \\
\hline & & Mental health problems & $4.45(14)$ \\
\hline \multirow[t]{2}{*}{ Mental health factor } & $4.73(4)$ & Personal factors & $4.09(21)$ \\
\hline & & Environmental factors & $4.45(15)$ \\
\hline \multirow[t]{5}{*}{ Mental health system } & $5.00(1)$ & Human rights & $4.45(16)$ \\
\hline & & Policies and plans & $4.82(5)$ \\
\hline & & Organizations & $5.00(1)$ \\
\hline & & Human resources & $5.00(2)$ \\
\hline & & Finance & $5.00(3)$ \\
\hline \multirow[t]{3}{*}{ Mental health service } & $5.00(1)$ & Mental health promotion and prevention & $4.55(13)$ \\
\hline & & Early interventions & $4.82(6)$ \\
\hline & & Treatment/Rehabilitation & $4.82(7)$ \\
\hline \multirow[t]{9}{*}{ Quality of mental health services } & $4.45(5)$ & Continuity & $4.91(4)$ \\
\hline & & Adequacy & $4.64(11)$ \\
\hline & & Accessibility & $4.73(10)$ \\
\hline & & Safety & $4.36(18)$ \\
\hline & & Effectiveness & $4.45(17)$ \\
\hline & & Efficiency & $4.27(19)$ \\
\hline & & Integrity & $4.82(8)$ \\
\hline & & Equality & $4.64(12)$ \\
\hline & & Continuity & $4.82(9)$ \\
\hline
\end{tabular}

mental health activities conducted in the area of mental health including services for the prevention, treatment, and rehabilitation of mental disorders, and 'Quality of mental health' includes indictors to measure whether mental health services enhance the level of mental health and whether such services are provided based on evidence.

By reviewing indicators developed in Korea and major foreign countries presented above, we collected around 600 in- dicators. Then, in consideration of their redundancy and availability, the principles of indicator development in this study, and the indicator system, we reduced them into 22 indicators on mental health status, 8 on mental health factor, 29 on mental health system, 38 on mental health service and 27 on the quality of mental health services, so a total of 124 indicators in the 1st questionnaire. 


\section{Expert questionnaire survey}

We conducted the 1st and 2nd questionnaire surveys with experts recommended by academic societies related to mental health in Korea. In detail, we recruited 19 participants who have expertise in the area under investigation from the following societies: Korean Neuropsychiatric Association, Korean Society of Clinical Psychology, Korean Association of Mental Health Social Workers, and Korean Academy of Psychiatric and Mental Health Nursing.

The purpose of the surveys was to collect the experts' opinions on the fitness of mental health indicators developed by the authors. Based on the results of the 1st questionnaire survey, the 2 nd questionnaire was developed through adding new indicators and revising the terms of indicators. The 1st questionnaire survey presented each expert indicator categories and 124 indicators developed by the authors, and had them rate the importance of each indicator domain/subdomain and item on a 5-point scale. Then, the importance of the indicator categories and items was assessed by the mean score and the proposed indicators were revised.

\section{RESULTS}

\section{Indicator categories}

In the results of the questionnaire survey on the suitability of indicator category, adequacy was high in order of mental health system, mental health service, mental health status, the quality of mental health services, and mental health factor among the 5 higher domains. Among the subdomains, those belonging to mental health system such as policies and plans, organizations, finance, and human resource, and those belonging to mental health service such as early interventions, treatment and rehabilitation attained a high score, showing high consistency with the results on the fitness of the 5 higher domains. In the questionnaire for assessing the importance of individual indicators, 40 out of the 124 indicators got a mean score of 4 or higher.

We developed the 2nd questionnaire containing a total of 127 indicators by revising terms and adding new indicators based on experts' opinions collected in the 1stt questionnaire survey. The 2nd questionnaire survey presented the results of the 1st survey and the revised questionnaire. As in the 1st questionnaire survey, the respondents rated the importance of each indicator category and item at a 5-point-scale, and then the fitness and importance of the indicator categories and individual indicators were assessed by the mean score. In the 2nd questionnaire survey, the suitability of mental health system and mental health services was also rated high and this result was mostly consistent with the results on the subdomains. To put it concretely in the results on the subdomains, 'policies and plans,' 'organizations,' 'human resources' and 'finance' belonging to mental health system, and 'early interventions' and 'treatment' belonging to mental health service showed high importance (Table 3).

\section{Mental health indicators}

In the results of expert survey on individual indictors, the number of indicators scoring 4 or higher was 59 out of 127 , which was 19 larger than that in the 1st survey. Among the top 30 indicators based on the mean score, 10 belonged to 'mental health system' and this is considered to suggest the importance of resources such as policies, organizations, human resources and finance in understanding the current situation of mental health and making related policies in Korea. Moreover, indicators in the subdomain of 'mental health problem' ranked high. In particular, 'suicide rate' ranked first probably because of the rapidly increasing number of suicides. Besides, the annual prevalence of mental disorders, depression and alcoholism was found to be an important indicator. It is also considered necessary to measure social and economic burdens caused by mental disorders including socioeconomic expenses resulting from mental disorders and suicides (Table 4).

\section{DISCUSSION}

As a preliminary study for developing mental health indicators that reflect the current situation of Korea, this study reviewed mental health indicators in Korea and other countries and proposed individual indicators in the domains of mental health status, mental health factor, mental health system, mental health service, and the quality of mental health services.

These indicators include the objectives of mental health suggested in national health policies such as Health Plan and the objectives of national mental health plans suggested by the National Mental Health Commission. Moreover, we aimed to develop indicators that can assess the current situation of mental health, suggest the future directions of policies, and monitor the quality of current mental health services and evaluate its trend. In particular, we included equality as a quality indicator in order to measure difference in the quality of mental health among areas and ultimately to spot inequalities among areas and redistribute resources in this age of decentralization. What is more, we tried to develop internationally comparable indicators by including mental health indicators used in international organizations such as WHO and OECD and foreign countries.

Various socioeconomic changes such as economic crisis, unemployment and poverty experienced by our society are becoming the risk factors of mental health causing chronic mental disorders as well as depression, suicide, stress and addiction. 
Table 4. Thirty key mental health indicators

\begin{tabular}{|c|c|c|c|}
\hline Domain & Subdomain & Indicator & $\begin{array}{l}\text { Mean of importance } \\
\text { (ranking) }\end{array}$ \\
\hline \multirow{7}{*}{$\begin{array}{l}\text { Mental health } \\
\text { status }\end{array}$} & Positive mental health & Subjective health awareness & $4.27(27)$ \\
\hline & Mental health problems & Annual prevalence of mental disorders (except alcohol and nicotine) & $4.64(5)$ \\
\hline & & Annual prevalence of depression & $4.64(6)$ \\
\hline & & Annual prevalence of alcoholism & $4.36(21)$ \\
\hline & & Suicide rate & $4.91(1)$ \\
\hline & & Burden caused by mental disorders (disability-adjusted life years, DALY) & $4.73(3)$ \\
\hline & & Socioeconomic expenses of suicide & $4.27(28)$ \\
\hline $\begin{array}{l}\text { Mental health } \\
\text { factor }\end{array}$ & Environmental factors & Social support & $4.27(29)$ \\
\hline \multirow{10}{*}{$\begin{array}{l}\text { Mental health } \\
\text { system }\end{array}$} & Human rights & The rate of discharge order by the Mental Health Judgment Committee & $4.36(22)$ \\
\hline & Policies and plans & $\begin{array}{l}\text { The percentages of cities, counties and wards with suicide prevention } \\
\text { projects }\end{array}$ & $4.27(30)$ \\
\hline & & $\begin{array}{l}\text { The adequacy of identifying mental health projects and deriving } \\
\text { solutions }\end{array}$ & $4.73(4)$ \\
\hline & & The rationality of setting the goals of mental health projects & $4.55(9)$ \\
\hline & & The adequacy of mental health project planning & $4.55(10)$ \\
\hline & Organizations & $\begin{array}{l}\text { The rate of installation and operation of psychiatric patients' residential } \\
\text { facilities (social rehabilitation centers, residential facilities, etc.) }\end{array}$ & $4.36(23)$ \\
\hline & Human resources & Supply of human resources for community mental health & $4.55(11)$ \\
\hline & & $\begin{array}{l}\text { No. of mental health professionals (clinical psychologists, social } \\
\text { workers, and mental health nurses) per 100,000 persons }\end{array}$ & $4.45(15)$ \\
\hline & Finance & The rate of increase in budgets for mental health projects & $4.45(16)$ \\
\hline & & The percentage of expenditure in mental health projects & $4.64(7)$ \\
\hline \multirow{5}{*}{$\begin{array}{l}\text { Mental health } \\
\text { service }\end{array}$} & Early interventions & Counseling and treatment rate after suicide attempt & $4.36(24)$ \\
\hline & Treatment/Rehabilitation & The rate of increase in mental disorder treatment & $4.82(2)$ \\
\hline & & Mean admission days for mental disorders & $4.55(12)$ \\
\hline & & No. of inpatients at mental health institutions per 100,000 persons & $4.36(25)$ \\
\hline & & The registration/management rate of psychiatric patients & $4.45(17)$ \\
\hline \multirow{7}{*}{$\begin{array}{l}\text { Quality of } \\
\text { mental health } \\
\text { services }\end{array}$} & Adequacy & Long-term hospitalization rate & $4.45(18)$ \\
\hline & Effectiveness & Rehospitalization rate within 30 days from discharge & $4.64(8)$ \\
\hline & & Discontinuation rate of acute (first-episode) treatment & $4.55(13)$ \\
\hline & Efficiency & The rate of decrease in psychiatric patients' hospital stay & $4.55(14)$ \\
\hline & & Balance of expenditure between hospitals and community services & $4.45(19)$ \\
\hline & & The rate of increase in the number of beds at the Psychiatric Department & $4.36(26)$ \\
\hline & Integrity & Employment of people with mental disorders & $4.45(20)$ \\
\hline
\end{tabular}

Mental health services for solving these problems are faced with diverse challenges in addition to their traditional tasks like chronic mental disease patients' returning to community, higher effectiveness of treatment services, human rights promotion, and enhanced quality of life. Although the mental health system of Korea has achieved quantitative expansion steadily including the increase in the number of mental health institutions and community mental health centers since the
Mental Health Act in 1995, it is still incompetent to cope with various mental health problems. ${ }^{17}$ In this situation, it is considered very desirable to conduct research for developing mental health indicators that represent the current state of mental health and mental health system and the quality of mental health services comprehensively.

As the indicators developed in this study targeted only adults not children, adolescents or elderly people, however, fur- 
ther research is required on the tasks below for the use of the results of this study. First, we need to obtain the values of the indicators using the indicator calculation models in order to monitor the current situation of mental health in Korea and improve the unmet needs. That is, by monitoring changes in the calculated values of the indicators, we may be able to evaluate the performance of government policies and monitor the trends of mental health. In other words, we can lay the base for a system to monitor national mental health policies through assessing the level and performance of mental health policies according to the directions and objectives of national mental health policies and through periodically monitoring national mental health policies for providing information necessary in policy making. Second, we need to accumulate indicators continuously and analyze them periodically, and utilize the results as materials for effective policy making. Third, we need to regularize national surveys with annual refinement of the developed mental health indicators and to develop standardized questionnaires for the surveys. Fourth, future studies developing dimensional mental health indicators are warranted because it is also important to measure the status of mental health not only categorically but also dimensionally.

The ultimate objectives of the development of mental health indicators are to find unsatisfactory parts or new needs by surveying the current state of mental health and mental health services, to reflect them in policies for high-quality mental health services, and ultimately to enhance people's mental health level. The mental health indicators proposed in this study are expected to be useful tools contributing to improving people's mental health by assessing the performance of mental health policies in connection to mental health problems and services, analyzing trends in mental health problems and mental health policies over time, and providing high-quality mental health services.

\section{Acknowledgments}

This study was conducted with the support of Lee Si-Hyung Social Psychiatry Research Fund of the Korean Foundation of Neuropsychiatric Research (DHA and SR) and the National Center for Mental Health Research and Education of Seoul National Hospital (HH). The authors would also like to acknowledge the contributions of the participating experts: Jeongyee Bae, RN, PhD, Inje University; Yong-Mae Baek, PhD, Catholic University of Daegu; An Kee Chang, MD, Seoul National Hospital; Duk Hee Chun, $\mathrm{PhD}$, Tongwon College; Duck-Gyu Kang, PhD, Haein Mental Health Center; Donghyeon Kim, MD, Choongmoosarang Hospital; Sun Ah Kim, RN, $\mathrm{PhD}$, Yonsei University; Yoon Kim, MD, PhD, Seoul National University; Jong-Eun Lee, RN, PhD, Inha University; Jonggook Lee, MD, Yong-In
Mental Hospital; Woo Kyeong Lee, PhD, Yong-In Mental Hospital; Yu Jin Lee, MD, PhD, Gachon University; Kyoung A Nam, RN, PhD, Ajou University; Jong-Woo Paik, MD, PhD, Kyung Hee University; Yongjin Seo, MD, Yong-In Mental Hospital; Jun Mo Sung, PhD, Korea Nazarene University; Hae-Joo Yoon, MA, Seoul National Hospital.

\section{REFERENCES}

1. Cho MJ. The Epidemiological Survey of Mental Disorders in Korea. Seoul: Ministry of Health and Welfare; 2011.

2. 10 facts on the global burden of disease. Available at: http://www.who. int/features/factfiles/global_burden/en/index.html. Accessed May 7, 2012.

3. World Health Organization. The Global Burden of Disease: 2004 Update. Geneva: World Health Organization; 2008.

4. Herrman H, Saxena S, Moodie R, editors. Promoting Mental Health: Concepts, Emerging Evidence, Practice. Geneva: World Health Organization; 2005.

5. World Health Organization. Constitution of the World Health Organization. Geneva: World Health Organization; 1948.

6. Yoon CK, Yoon BJ, Lee JH, Kim YS. A study on development of health indicator system in Korea. Korean J Health Policy Admin 2003;13:4466.

7. World Health Organization. Mental Health Policy and Service Guidance Package: Mental Health Information Systems. Geneva: World Health Organization; 2005.

8. Hermann R, Mattke S, Members of the OECD Mental Health Care Panel. Selecting Indicators for the Quality of Mental Health Care at the Health Systems Level in OECD Countries. OECD Health Technical Papers NO. 17. Paris: Head of Publications Service, OECD; 2004.

9. Saxena S, Lora A, van Ommeren M, Barrett T, Morris J, Saraceno B. WHO's Assessment Instrument for Mental Health Systems: collecting essential information for policy and service delivery. Psychiatr Serv 2007;58:816-821.

10. MINDFUL-Mental Health Information and Determinants for the European Level. Available at:?http://info.stakes.fi/mindful/EN/frontpage. htm. Accessed May 8, 2012.

11. Mental Health Statistics Improvement Program's Consumer-Oriented Mental Health Report Card. Available at: http://www.mhsip.org/reportcard/. Accessed May 8, 2012.

12. National Mental Health Performance Subcommittee. Key Performance Indicators for Australian Public Mental Health Services: Technical Specification Summary. Canberra: Department of Health and Ageing, Commonwealth of Australia; 2008.

13. Department of Health. NHS Performance Ratings: Acute Trusts, Specialist Trusts, Ambulance Trusts, Mental Health Trusts 2001/02. London: Department of Health Publications; 2002.

14. Commission for Health Improvement. Available at: http://www.chi.nhs. uk/Ratings/Trust/Overview/mht_overview.asp. Accessed May 8, 2012.

15. Parkinson J. Establishing a Core Set of National, Sustainable Mental Health Indicators for Adults in Scotland: Final Report. Edinburgh: NHS Health Scotland; 2007.

16. Suh MK, Kim HR, Suh T, Sun WD, Shin YJ, Choi EJ, et al. Establish of New Health Plan 2010. Seoul: Korea Institute for Health and Social Affairs, Ministry of Health and Welfare; 2005.

17. National Mental Health Commission. 2007 National Mental Health Commission Report. Seoul: Ministry of Health, Welfare and Family Affairs; 2008 . 